\title{
O ENSINO DE ARTE NA ESCOLA NOVA EM MINAS GERAIS NA PERSPECTIVA DA REVISTA DO ENSINO ENTRE OS ANOS DE 1927 E 1933
}

\author{
The art teaching at the Escola Nova in Minas Gerais from the perspective of the \\ Revista do Ensino between 1927 and 1933 \\ La enseñanza del arte en la Escola Nova en Minas Gerais bajo la perspectiva de la \\ Revista do Ensino entre los años 1927 y 1933
}

\section{DENISE PERDigÃo PEREIRA ${ }^{1}$}

\section{Resumo}

Este artigo objetiva analisar o ensino de arte na Escola Nova em Minas Gerais. Para tanto, foram tomados, como fontes primárias, textos sobre as disciplinas de Desenho e Trabalhos Manuais publicados na Revista do Ensino entre os anos de 1927 e 1933, adotando-se a análise documental como metodologia para a investigação. O período abordado caracteriza a introdução de importantes mudanças na educação deste estado, destacando-se a divulgação e a tentativa de implantação de novos métodos de ensino no curso primário. Tal aspecto, contudo não eliminou a permanência de uma visão tradicional quanto ao papel atribuído à arte na educação primária. Assim, ao lado de uma concepção de ensino de arte mais ampla, voltada para a valorização do potencial criativo infantil, coexistiu na Revista uma visão utilitarista da arte, marcada pela ênfase na contribuição das atividades de Desenho e Trabalhos Manuais para o preparo profissional.

Palavras-chave: Ensino de Arte; Escola Nova; Minas Gerais; Revista do Ensino.

\footnotetext{
${ }^{1}$ Doutorado em Educação Artística pela Universidade do Porto (Portugal). Professora do Instituto Federal de Minas Gerais (Brasil). E-mail: perdigaodenise@yahoo.com.br
} 


\begin{abstract}
This article aims at analyzing the art teaching in the Escola Nova, Minas Gerais. In order to realize the analysis, texts about the Disciplines of Drawing and Craftwork, published in the Revista do Ensino between 1927 and 1933, were used as primary sources. The methodology involved document analysis. The time period approached in the study marks the introduction of important changes in the education of the province, in special the public dissemination and the attempt to implement new teaching methods in the first school grade. However, this aspect did not extinguish the traditional viewpoint referring to the role attributed to the art in the first grade education. Therefore, a utilitarian viewpoint of the Revista itself coexisted with a broader concept of teaching oriented towards the valorization of the creative potential of children, marked by the emphasis in the contribution of the activities of Drawing and Craftwork to the professional training.
\end{abstract}

Keywords: Art Teaching; Escola Nova; Minas Gerais; Revista do Ensino.

\title{
Resumen
}

Este artículo objetiva analizar la enseñanza del arte en la Escola Nova en Minas Gerais. Para lo cual se utilizaron, como fuentes primarias, textos sobre las asignaturas de Dibujo y Trabajos Manuales publicados en la Revista do Ensino entre los años 1927 y 1933, se adoptó un análisis documental como metodología para la investigación. El período abordado caracteriza la introducción de importantes cambios en la educación del estado de Minas Gerais, destacándose la divulgación y la búsqueda de la implantación de nuevos métodos de enseñanza en el curso elemental. No obstante, tal aspecto no excluyó la permanencia de una visión tradicional en cuanto al papel atribuido al arte en la educación primaria. Así, al lado de una concepción de enseñanza de arte más amplia, que valora el potencial creativo infantil, coexistió en la Revista una visión utilitarista de las asignaturas artísticas, marcada por el énfasis en la contribución de las actividades de Dibujo y Trabajos Manuales para el preparo profesional.

Palabras clave - Enseñanza del Arte; Escola Nova; Minas Gerais; Revista do Ensino. 


\section{Introdução}

Considerando o número restrito de pesquisas relacionadas à história do ensino de arte no Brasil, bem como a inexistência de pesquisas mais aprofundadas sobre o contexto mineiro, esse artigo tem como objetivo descrever e discutir as concepções de ensino de arte em Minas Gerais veiculadas durante o movimento pedagógico conhecido como Escola Nova, entre os anos de 1927 e 1933.

Tal abordagem pretende contribuir para um melhor entendimento a respeito da trajetória da arte na educação escolar e, consequentemente, para uma maior compreensão dos entraves que marcam esse campo.

Em pesquisa sobre a história do ensino de arte no Brasil, Barbosa (1986, p.12) elege como objetivo do seu estudo: "conscientizar o professor de arte acerca das raízes de seus métodos, o que o auxiliará a refletir acerca da atualidade e da propriedade desses métodos hoje".

Contudo, a escassez de estudos sobre o assunto tem se constituído em empecilho para o desenvolvimento de investigações no âmbito do ensino de arte no Brasil. Tal proposição é confirmada por Barbosa:

A principal dificuldade para a realização deste trabalho foi a ausência de fontes de informação, uma vez que não há nenhum estudo sobre a evolução do ensino de Arte na escola primária e secundária no Brasil (...). As referências que se encontram sobre arte na escola e seu ensino são pouco frequentes, esparsas e excessivamente gerais (BARBOSA, 1986, p.13).

Apesar das dificuldades encontradas por Barbosa no levantamento de fontes, sua pesquisa se mostra importante para a compreensão da história do ensino de arte no Brasil. $\mathrm{O}$ estudo cobre o período que vai desde a introdução oficial do ensino artístico no país, no século XIX, até as primeiras décadas do século XX, com a influência da Psicologia Experimental no ensino do Desenho. Porém, considerando o estado de São Paulo como pioneiro na introdução de tal abordagem, Barbosa restringirá sua análise a esse estado.

Outro importante estudo desenvolvido por Barbosa (2002), relacionado ao assunto, tem como foco de análise a influência do pensamento do filósofo norte-americano John Dewey (1859 - 1952) no ensino de arte no Brasil. A autora apresenta os principais propagadores das ideias de Dewey por meio das reformas de ensino brasileiras ocorridas no final da década de 1920. Mereceu destaque em sua investigação a professora de desenho suíça, Artus Perrelet que, em 1929, veio a Minas Gerais para a Reforma de Ensino Mineira. Assim, o movimento escolanovista em Minas Gerais é indiretamente tratado por Barbosa. Porém, a autora se detém na figura de Perrelet e na influência de Dewey em sua concepção de ensino.

Ferraz e Fusari (1992) também apresentam uma pequena introdução à história do ensino da arte no Brasil. Em seu livro "Arte na Educação Escolar", as autoras relacionam as abordagens metodológicas predominantes no ensino de arte no Brasil às tendências pedagógicas que marcaram e marcam as práticas escolares no país, envolvendo, portanto o período da Escola Nova. O modo abrangente como o assunto é abordado, entretanto, revela grandes lacunas na discussão sobre o ensino de arte em cada uma dessas tendências. 
A escassez de pesquisas sobre a história do ensino de arte em Minas Gerais e, ainda, a busca por uma maior aproximação com as concepções de ensino vigentes na Escola Nova, impuseram a necessidade de aprofundamento do tema. Acredita-se que a perspectiva de análise aqui desenvolvida mostra-se relevante na medida em que esse foi um período fecundo para a educação do estado de Minas. Este momento foi marcado pela introdução de importantes medidas no campo do ensino de arte. Algumas dessas medidas foram: a realização do Congresso de Instrução Primária, em 1927, tendo como um dos pontos de discussão as diretrizes a serem tomadas no ensino de Desenho e de Trabalhos Manuais; a reforma dos programas de ensino de Desenho e Trabalhos Manuais dos cursos primário e normal, em 1928; a ampla divulgação de novos objetivos, conteúdos e métodos no ensino artístico, através de conferências pedagógicas e da Revista do Ensino publicada neste período. Destaca-se, ainda, a vinda da missão pedagógica europeia para Minas Gerais, em 1929, já que dois de seus integrantes, Artus Perrelet e Jeanne Milde, possuíam formação na área de arte (PEREIRA, 2006).

A compreensão do significado atribuído à arte na educação escolar durante a Escola Nova pode lançar luzes sobre as concepções de ensino de arte presentes na atualidade, uma vez que o pensamento educacional difundido durante o escolanovismo alcança, ainda hoje, grande repercussão na formação dos professores brasileiros (LIBÂNEO, 1990).

\section{O Ensino de Arte na Escola Nova}

A Escola Nova em Minas Gerais pode ser definida como um movimento pedagógico marcado pela recusa ao modelo de ensino vigente até então - a Pedagogia Tradicional. ${ }^{2}$

Em linhas gerais, pode-se afirmar que a principal diferença entre a Escola Nova e a Pedagogia Tradicional reside no modo como a educação foi desenvolvida em cada uma dessas tendências. Se, por um lado, o modelo de ensino vigente anteriormente, a Pedagogia Tradicional, era associado a uma visão de educação que enfatizava cópias mecânicas e exercícios de repetição; por outro lado, a Escola Nova associava-se a uma visão de educação mais ampla, com a ação infantil concebida como elemento-chave para o aprendizado.

Em Minas Gerais, a introdução da Escola Nova aconteceu a partir da Reforma de Ensino Francisco Campos (1927/28), empreendida no governo de Antônio Carlos (1926 a 1930).

Segundo o artigo A Escola Activa, de Albano de Morais, publicado na Revista do Ensino, a Reforma de Minas teria o objetivo de introduzir os modernos métodos de educação.

Baseada no interesse, na cooperação e na iniciativa, a reforma transformou a escola no verdadeiro templo da educação, segundo os novos conceitos, isto é: - a educação considerada como desenvolvimento integral do indivíduo (REVISTA DO ENSINO, 1930, p.70).

\footnotetext{
${ }^{2}$ Para uma definição dos movimentos pedagógicos, incluindo a Escola Nova e a Pedagogia Tradicional, predominantes ao longo da história da educação no Brasil, ver: Libâneo (1990).
} 
A atividade de pensar, fundamental à escola, antes concebida como mero acúmulo de dados obtidos por meio de métodos verbais, passa a ser considerada de valor educativo quando envolve um exame profundo e prolongado, possível apenas em ambientes de alegria e interesse (REVISTA DO ENSINO, 1930).

Em contraposição ao método intuitivo, ${ }^{3}$ utilizado na Escola Tradicional, defendeu-se o desenvolvimento do método ativo:

Fazer a criança agir, eis o primeiro dever do mestre (...). Com essa obrigação estabelecida - fazer a criança agir - diremos adeus as cacetíssimas lições recitadas, às fórmulas, definições, generalizações, tão do gosto da escola antiga, coitada, que tanto mal nos fez, com a melhor das intenções (REVISTA DO ENSINO, 1930, p.11).

A valorização da atividade infantil como elemento importante para o aprendizado devese ao desenvolvimento da psicologia, no início do século XX, marcada por uma demonstração quase experimentalista de um velho aforismo da filosofia: nada está no intelecto que não tenha antes passado pelos sentidos.

Em uma atmosfera completamente isenta de verbalismos, os trabalhos escolares ganham uma intensidade e uma eficiência até então desconhecidas, e que só se explicam pelo respeito que aí se consagra à atividade criadora da criança, traço distintivo de sua natureza irrequieta (REVISTA DO ENSINO, 1930, p.11).

O reconhecimento da atividade criadora infantil como recurso valioso para a educação implicará, por sua vez, na valorização das atividades de Desenho e Trabalhos Manuais no contexto da Escola Nova.

Contudo, a ênfase dada ao método ativo, em contraposição ao método intuitivo, não significou, no período em questão, o abandono por completo da Pedagogia Tradicional.

Referindo-se ao movimento escolanovista, Fernando de Azevedo (1943, p.402) ressalta que ele foi marcado pela "pluralidade e confusões de doutrinas que mal se encobriam sob a denominação genérica de 'educação nova' ou de 'escola nova', suscetível de acepções muito diversas".

O caráter ambíguo e, em alguns casos, até mesmo contraditório, conferido às atividades de Desenhos e Trabalhos Manuais na Revista do Ensino, entre os anos de 1926 e 1933, confirma a proposição de Fernando de Azevedo.

No tópico seguinte serão discutidas algumas das concepções de ensino de arte presentes na Revista, destacando-se a pluralidade de orientações identificadas no documento.

\footnotetext{
${ }^{3} \mathrm{O}$ método intuitivo caracterizou-se pelo ensino através dos olhos, ou seja, por meio da observação dos aspectos das coisas.
} 


\section{A Revista do Ensino e as disciplinas de Desenho e Trabalhos Manuais}

A Revista do Ensino, publicada mensalmente sob a responsabilidade da Diretoria da Instrução de Minas Gerais entre os anos de 1925 e 1970, constitui-se em valioso documento a respeito da educação mineira. No ano de 1933, sua publicação cessaria, sendo retomada apenas em 1956.

O recorte dado neste artigo às publicações da Revista do Ensino corresponde ao período compreendido entre os anos de 1927 e 1933, momento em que nela fervilhavam as ideias escolanovistas.

Durante o período em que foi publicada, a Revista teve como objetivos orientar, estimular e informar os funcionários do meio educacional - professores, diretores, assistentes técnicos ${ }^{4} \mathrm{e}$ inspetores - a respeito dos novos métodos de ensino.

De acordo com o artigo 480 do Regulamento do ensino primário, a Revista do Ensino deveria possuir duas partes. A primeira delas, de caráter doutrinário, estaria destinada a:

Dirigir o professorado público do Estado, harmonizando seus esforços; Pô-lo ao corrente da evolução do ensino primário em todos os seus aspectos; Publicar-lhes os trabalhos ou extratos destes, quando de interesse didático (MINAS GERAIS, 1924, p.333-334).

Já a segunda parte da Revista, de conteúdo noticioso, veicularia publicações ligadas a:

Fatos e ocorrências locais, nacionais ou estrangeiras, que possam orientar os funcionários do ensino; dados estatísticos relativos à instrução; atos oficiais que interessem aos funcionários do ensino conhecer (MINAS GERAIS, 1924, p.333-334).

Observa-se, nos dois trechos acima, a importância concedida à Revista do Ensino para a definição dos rumos da educação mineira. No que se refere ao ensino de arte, objeto de interesse desta análise, o destaque dado nas publicações, entre os anos de 1927 e 1933, às atividades de Desenho e Trabalhos Manuais revela o caráter estratégico a elas conferido no movimento mineiro designado como Escola Nova. Percebe-se, no material analisado, uma quantidade considerável de publicações a respeito do assunto. Nessa perspectiva, torna-se relevante perguntar: Quais foram às concepções de arte e de ensino de arte identificadas nos documentos?

$\mathrm{Na}$ busca por responder a essa questão, será discutido no próximo tópico o modo como as atividades de Desenho e Trabalhos Manuais foram tratadas na Revista.

\subsection{O desenho na Escola Nova em Minas Gerais}

O primeiro texto sobre Desenho e Trabalhos Manuais na Revista data de 1927, com a publicação das teses discutidas no "Primeiro Congresso de Instrução Primária do Estado de Minas Gerais", ocorrido nesse mesmo ano. O evento teve como objetivo realizar um trabalho preparatório para a Reforma de Ensino Mineira Francisco Campos. Para tanto, foram organizadas comissões em torno dos assuntos que orientariam a reforma. Os temas discutidos foram: organização geral do ensino primário, questões de pedagogia, aparelhamento escolar, Desenho e Trabalhos Manuais e Educação Moral e Cívica (PEREIRA, 2006).

\footnotetext{
${ }^{4}$ Cargo estratégico criado pela Reforma Francisco Campos para a difusão das novas propostas nas escolas. A assistência técnica era responsável pela divulgação do ideário do governo, bem como pelo acompanhamento e controle das atividades em execução.
} 
A importância concedida às atividades de Desenho e Trabalhos Manuais na época pode ser percebida a partir da existência de uma sessão destinada exclusivamente à discussão dessas disciplinas. A comissão de Desenho e Trabalhos Manuais foi composta pelos seguintes nomes: Iracema de Macedo, Luíza Torres, Emília Truran, Anna Santa Cecília, Edgar Renault, Maria Otília Lopes, Margarida da Silva Santos, Noemi Schimitd, Marieta Brochado, Leonor Tafuri e Anibal Matos. ${ }^{5}$

A primeira tese discutida pela comissão sinaliza a influência das correntes artísticas modernas no modo de se conceber o desenho infantil: "O ensino do desenho, no curso primário, deve ser considerado como arte ou como meio intuitivo da criança exprimir o que imagina e representar o que vê?" (REVISTA DO ENSINO, 1927, p.490).

De acordo com alguns movimentos artísticos nascidos na Europa no início do século XX, tais como o Surrealismo e o Primitivismo, os desenhos de crianças, loucos e povos primitivos representariam uma forma de arte pura, genuína. A repercussão dessas ideias no Brasil deu-se, inicialmente, em São Paulo, a partir da Semana de Arte Moderna de 1922. Em Minas Gerais, o teor da primeira tese discutida na sessão de Desenho e Trabalhos Manuais do Congresso também revela a influência desse pensamento, uma vez que, indaga-se sobre o desenho infantil como forma de arte. Contudo, a resposta para tal questão faz supor que essa concepção não encontrou em Minas, pelo menos naquele momento, solo fértil para se desenvolver. ${ }^{6}$ Após debater a questão, a comissão chegou a seguinte conclusão: "O ensino do desenho no curso primário, deve ser considerado como meio educativo, visando desenvolver as faculdades da imaginação, observação e a educação da vista e das mãos" (REVISTA DO ENSINO, 1927, p.490).

Embora o desenvolvimento da faculdade da imaginação tenha sido ressaltado como um dos objetivos do ensino de desenho no curso primário, a preocupação para com o desenvolvimento da capacidade de observação e a educação da vista e das mãos revelam a forte influência da concepção educacional predominante no final do século XIX no ensino de desenho. Uma citação feita por Abílio César Pereira Borges (1882) em seu livro Geometria Popular, primeiro manual de desenho geométrico para as escolas primárias publicado no Brasil, revela a influência de ideias norte-americanas no congresso mineiro:

A educação do olho e da mão, o desenvolvimento do gosto pelo desenho, adquirido desde as primeiras idades nos jardins de infância, completadas pelo ensino do Desenho elementar nas escolas de primeiro e segundo grau e do desenho industrial nos do segundo grau (...) bastarão para fazer uma revolução nas manufaturas de nosso país (...) (BORGES, 1882, p.14 apud BARBOSA, 1986, p.54).

\footnotetext{
${ }^{5}$ Anibal Matos foi professor na Escola Normal, Inspetor do Ensino de Desenho e artista de destaque no contexto mineiro. De acordo com a professora Ana Maria Casasanta Peixoto, Edgar Renault Coelho era professor de Ciências da Escola Normal de Belo Horizonte. Ainda segundo a mesma autora, Marieta Brochado fazia parte do Corpo de Assistência Técnica, um dos órgãos responsáveis pela fiscalização do ensino no período. Quanto aos demais membros da comissão, não foi possível obter informações acerca de sua atuação no meio educacional (PEREIRA, 2006).

${ }^{6} \mathrm{O}$ interesse pela arte da criança e adolescente ganhou espaço no Brasil, especificamente em São Paulo, a partir do início da década de 1930. Tal fenômeno, contudo, não teve maior repercussão na educação formal, marcando a criação de escolas livres de arte para crianças e adolescentes. A artista Anita Malfatti (1860 - 1964) e o poeta e romancista Mário de Andrade (1893 - 1945) foram pioneiros no emprego da livre-expressão e do espontaneísmo como eixos norteadores das aulas de arte para esses dois grupos (BARBOSA, 1998).
} 
A citação expressa o teor utilitarista conferido ao ensino do desenho no Brasil desde o final do século XIX, considerando-o como condição para o desenvolvimento econômico do país.

A terceira, quarta e quinta teses referem-se, respectivamente, ao ensino da proporção e perspectiva, da observação visual e do estudo de sombras. A ênfase dada ao estudo de tais elementos fornece ainda indícios de uma influência da orientação neoclássica ${ }^{7}$ no ensino primário, difundida no país a partir da criação da Academia Imperial de Belas Artes, no Rio de Janeiro, por Dom João VI, em $1816 .^{8}$

Contudo, ao lado de uma concepção mais tradicional e utilitarista, percebe-se a existência de uma visão mais ampla a respeito do ensino do desenho, marcada possivelmente pela influência da psicologia ${ }^{9}$ no campo educacional. Assim, na sexta tese da Sessão de Desenho e Trabalhos Manuais discutiu-se a seguinte questão: "Ao iniciante deve condenar-se a cópia de estampas e gravuras?" (REVISTA DO ENSINO, 1927, p.491). A comissão definiu o seguinte:

Sim, porque se forçarmos as crianças a copiarem estampas ou gravuras, impediremos que se desenvolvam as ideias individuais e de personalidade, cansando a memória e esterilizando a inteligência das crianças (REVISTA DO ENSINO, 1927, p.491).

O teor da sétima tese, ao demonstrar uma nítida preocupação para com o respeito à individualidade da criança, assinala que esse foi um período de transição para o ensino de arte, quando concepções distintas e até mesmo contraditórias coexistiram na Revista.

\subsubsection{Influência de aspectos econômicos para a valorização do ensino do desenho}

A importância atribuída ao ensino do desenho para o desenvolvimento econômico do país foi um elemento recorrente na Revista do Ensino. Tal posicionamento identifica-se com a concepção educacional de Rui Barbosa (1849 - 1923), um dos intérpretes mais fiéis da corrente liberal no Brasil do início do século XX.10

Segundo Ana Mae Barbosa (2006), as ideias pedagógicas de Rui Barbosa tiveram grande influência no Brasil. A proposição da autora foi confirmada no movimento da Escola Nova em Minas Gerais. Dessa forma, em um artigo publicado na Revista, o autor Anibal Matos (1933, p.5) destaca a importância dada à educação artística infantil nos países europeus, desde a década de 1910. Assim como Rui Barbosa, Anibal Matos considerava que desenho e modelagem deveriam ser partes obrigatórias da educação no Brasil. Tal fator é visto por ambos como imperativo para o desenvolvimento da indústria e da arte brasileira. De

\footnotetext{
${ }^{7}$ De acordo com a Enciclopédia de Artes Visuais Itaú Cultural, o Neoclassicismo "foi um movimento cultural europeu, do século XVIII e parte do século XIX, que defende a retomada da arte antiga, especialmente Greco-romana, considerada modelo de equilíbrio, clareza e proporção". Disponível em: http://www.itaucultural.org.br/aplicexternas/enciclopedia_ic/index.cfm?fuseaction=termos_texto\&cd_verbete=3 61. Acesso em: 13 nov. 2013.

${ }^{8}$ Sobre a Academia e sua orientação metodológica no ensino do desenho, ver: Barbosa (2002, p.31-41).

${ }^{9}$ Sobre a influência da psicologia na educação mineira, sobretudo no ensino de desenho, ver tópicos 2.5 e 2.5.2.

${ }^{10}$ Ver BARBOSA (1986).
} 
acordo com Anibal Matos, o "progresso e riqueza" alcançados pela América do Norte, no final do século XIX, foi consequência da ênfase dada naquele país ao ensino de desenho nas escolas primárias.

Mas, se no século XIX o desenho seria considerado, sob a influência da pedagogia, como arte plástica, no século XX, a ênfase a ele dada "continuaria a favor de sua inclusão na escola primária e secundária, as quais se orientarão no sentido de considerá-lo mais uma forma de escrita" (BARBOSA, 2002, p.34).

Tal tendência, entretanto, já vinha se desenvolvendo no Brasil desde fins do século XIX. Para Rebouças, engenheiro de destaque que exerceu importante atividade política pela extinção da escravatura: "O desenho é um complemento da escrita, da caligrafia e da ortografia. É o meio de comunicar a ideia de uma figura do mesmo modo que a escrita é o modo de comunicar um pensamento" (REBOUÇAS, 1878 ${ }^{11}$ apud BARBOSA, 1986, p.34).

Um artigo publicado na Revista em 1930, acerca de uma palestra proferida por Affonso Roquette, professor da Escola Normal de Paracatu, revela notável semelhança com a concepção de Rui Barbosa sobre o ensino de desenho:

Meio de expressão valiosíssimo, é servindo-se dele (do desenho) que o professor primário, desprovido por ventura de materiais didáticos adequados, ilustra e esclarece dúvidas, substituindo o verbalismo, nem sempre atraente por traços sintéticos (REVISTA DO ENSINO, 1930, p.33).

Para além do contexto escolar, o desenho também teria uma função bastante específica: "De um modo geral, ainda é por essa feição comunicativa do desenho, que se torna fácil e rápido o entendimento entre o patrão e o operário; o chefe de oficina e o discípulo; o professor e o arquiteto, o pedreiro, o marceneiro, etc.”(REVISTA DO ENSINO, 1930, p.33).

O desenho, nessa perspectiva, foi associado a uma concepção de educação utilitarista, tendo como ênfase a satisfação de necessidades práticas, ligadas essas, por sua vez, a situações do cotidiano:

Aproveitando e cultivando racionalmente a tendência inata que a criança manifesta para o desenho, tem a escola primária por objetivo, no ensino dessa arte, torná-la um recurso eficaz de que o aluno possa lançar mão nas necessidades ordinárias de sua vida prática (REVISTA DO ENSINO, 1930, p.34).

\subsubsection{O espaço do desenho no programa escolar}

Em Minas Gerais, a Reforma do Ensino empreendida por Francisco Campos garantiu às disciplinas de Desenho e Modelagem uma organização especial. O desenho deveria ser aproveitado em todas as oportunidades, associando-o às matérias do curso primário (REVISTA DO ENSINO, 1933, p.11). A defesa de tal associação tinha por base uma concepção do desenho "como matéria de primeiro plano, como de fato é, em face dos programas da escola moderna” (REVISTA DO ENSINO, 1933, p.12).

\footnotetext{
${ }^{11}$ ANDRÉ REBOUÇAS. Generalização do ensino do desenho. O Novo Mundo, nov.1878, p.246.
} 
Diversas publicações na revista revelam que o ensino de desenho foi considerado como a linguagem artística mais importante para a educação primária no período. Segundo Affonso Roquette, professor da Escola Normal de Paracatu, "ramo o mais importante das Belas Artes, que nele encontra a sua base sólida, é ao desenho que devemos as obras primas da pintura, escultura, gravura e arquitetura" (REVISTA DO ENSINO, 1930, p.32).

A concepção do desenho como base para as outras artes tem suas origens, no Brasil, com o neoclassicismo. Conforme apontado no tópico 2.1, sua propagação no país se deu a partir da implantação da Academia Imperial de Belas Artes no Rio de Janeiro. Uma das principais características do neoclassicismo nas artes plásticas foi o predomínio do desenho sobre a cor. Em um texto publicado na Revista do Ensino, em 1930, intitulado como $O$ Desenho na Escola Primária, tal concepção mostra-se evidente. Para o autor, Affonso Roquette, era preciso que os alunos fossem ensinados a distinguir a função particular do desenho da função particular da pintura, "noções comumente confundidas pelas crianças". Roquette explica: "O desenho é a base da pintura como o alicerce é para o edifício". Assim, a pintura deveria "oferecer perfeita aliança entre forma e cor". Entretanto, a cor teria uma importância secundária: "A cor, porém, não é parte integrante dos corpos, é como um revestimento que eles pedem à luz; ao passo que a forma é imutável, constituindo por si só a individualidade do objeto" (REVISTA DO ENSINO, 1930, p.33-4).

\subsubsection{As atividades de desenho recomendadas na revista}

A Revista promoveu, entre os professores atuantes nas escolas de Minas Gerais, concursos para a publicação de aulas consideradas como modelo. Dentre as aulas enviadas para o concurso, no mês de fevereiro de 1929, considerou-se "de justiça destacar" uma de desenho, cujo assunto foi "Composição decorativa com base geométrica". Em linhas gerais, trabalhou-se, na aula, com a definição e o desenho de formas geométricas, tais como o quadrado, o triângulo e o círculo. Para tanto, a professora deveria traçar essas formas no quadro negro. Em seguida, apresentaria aos alunos a definição dessas formas. Na última etapa da aula, momento chamado de "Expressão", seria confeccionada, por cada um dos alunos, uma toalhinha para cobrir pratos. A toalhinha deveria ser decorada com as formas geométricas aprendidas na aula (REVISTA DO ENSINO, 1929, p.38).

No ano de 1930, a Revista publicou um artigo sobre as impressões de uma professora mineira a respeito do ensino em uma escola do Distrito Federal. A Escola se chamava Rodrigues Alves e foi considerada como a primeira a se interessar pelos novos métodos da Escola Nova no Brasil. Assim, ela se constituiu uma referência importante no contexto educacional em questão.

A autora do artigo, cujo nome não foi possível identificar, teve a oportunidade de assistir diversas aulas na escola. Um ponto importante de suas observações refere-se ao modo como as crianças eram avaliadas: os testes eram dados como exercícios, o que provavelmente influiria positivamente nos resultados alcançados pelos alunos. De acordo com a professora mineira, "Muitas vezes alunos preparados, inteligentes, fazem provas fraquíssimas, e viceversa". Com a adoção dos exercícios como estratégia para a avaliação dos alunos em desenho, observou-se que a porcentagem de êxito na disciplina chegou a 70\%, maior índice que todas as outras (REVISTA DO ENSINO, 1930, p.49). 
Ainda sobre a disciplina de desenho, a autora afirma:

Há um interesse particular pelos testes de desenho. O inspetor conseguiu, mesmo, um curso de desenho e modelagem na Escola de Belas Artes, para as professoras do $8^{\circ}$ distrito. Fornece sempre orientações às professoras sobre as diversas matérias do ensino (REVISTA DO ENSINO, 1930, p.40).

Embora o artigo não apresente diretrizes para a realização dos testes de desenho, a professora mineira dedica algumas páginas à descrição detalhada de uma "Orientação sobre cores" dada às professoras pelo inspetor. Tal orientação envolveu o estudo: das cores primárias, binárias (secundárias) e terciárias. Trabalhou-se ainda com o conceito de: cores complementares, quentes e frias; tonalidades e gama ou escala de tons; contraste e harmonia. Interessante destacar que o assunto abordado pelo inspetor refere-se a conteúdos bastante específicos do campo da arte. Esse talvez seja mais um indício da valorização atribuída ao ensino de arte na Escola Nova.

A publicação na Revista das observações da professora mineira a respeito das aulas de uma escola do Distrito Federal, considerada como referência para o país, confirma o interesse pela divulgação e circulação de ideias favoráveis à solidificação da Escola Nova em Minas Gerais. Além disso, o fato de a professora ter dedicado várias páginas à descrição de conteúdos relativos ao ensino de Desenho também confirma a importância atribuída a essa disciplina na educação mineira do período.

Outro artigo da Revista, intitulado "O desenho na escola primária," também apresentou indicações sobre os tipos de atividade que deveriam ser desenvolvidas para o ensino de desenho. São elas: exercícios em trabalhos gráficos sobre linhas, seguidos de pequenas aplicações em esboços de objetos, estudos ao natural e de imaginação. Ainda que não fique claro em que consistiram os "exercícios em trabalhos gráficos sobre linhas", é interessante destacar que tal tarefa teve como um de seus objetivos preparar "o aluno para a escrita, que é, aliás, uma modalidade do desenho". Tal proposição confirma mais uma vez a afirmação de Barbosa (1986) sobre a orientação dada ao ensino de Desenho no início do século XX, apresentada no tópico 3.1.1.

Além da comparação estabelecida entre o desenho e a escrita, é importante também mencionar a sua relação com as atividades propostas para o curso primário como um todo. Foi muito comum, na época, o desenvolvimento de unidades de estudo a partir de Centros de Interesse. ${ }^{12}$ As atividades de desenho geralmente sugeridas nos planos dessas lições contemplaram desenhos espontâneos ou realizados ao ar livre sobre os assuntos estudados. Dois planos de lições publicados na Revista, ambos no ano de 1930, tiveram como centro de interesse os "Chapéus" e uma "Fábrica de tintas".

12 Orientação pedagógica desenvolvida pelo educador e psicólogo belga Jean-Ovide Decroly (1871-1932). Nessa técnica, os temas a serem estudados devem ser apresentados no seu todo, e não divididos em disciplinas. 


\section{Desenvolvimento do sentido estético: contribuições da psicologia e influência do romantismo}

Conferências realizadas na Escola Normal Modelo de Belo Horizonte foram, em alguns casos, publicadas na Revista do Ensino. Em uma delas, datada de 1929, a conferencista Marília Emília Castro $^{13}$ (REVISTA DO ENSINO, 1929, p.8) apresentou como tema a Educação Estética da Infância. De acordo com a autora, tal assunto não estava sendo cuidado "com o interesse que devia merecer, dada a sua grande importância" (REVISTA DO ENSINO, 1929, p.8).

Castro começa por caracterizar o senso estético da criança contrastando-o com o do adulto. Segundo a conferencista, para julgar o senso estético de um adulto, seria necessário começar pela avaliação de sua capacidade de apreciação. O mesmo não aconteceria com relação à criança. Neste caso, dever-se-ia, em primeiro lugar, observar as suas manifestações criadoras. Isso porque, para a autora, na criança, "a tendência artística se manifesta mais acentuadamente pela produção que pela apreciação" (REVISTA DO ENSINO, 1929, p.9). Diferentemente do adulto, mas tal como no artista, na criança, as faculdades de apreciação e produção encontravam-se juntas. De acordo com Castro: "A necessidade de reagir é tão imperiosa no artista quanto na criança, pois possuem ambos, grande poder de vibração" (REVISTA DO ENSINO, 1929, p.9).

Assim, para a autora, o estudo da tendência estética da criança deveria basear-se em sua tendência criadora. Sob a influência da psicologia, Castro ainda considera que a forma produtiva seria reveladora do temperamento infantil. Em síntese, foi considerado necessário observar as tendências estéticas da criança e o modo como essas tendências se manifestavam.

Ainda na perspectiva de Castro, tal assunto estava sendo tratado com inteiro descaso entre os estudiosos do tema, com exceção para as pesquisas envolvendo o desenho. $\mathrm{Na}$ tentativa de preencher essa lacuna, a autora colheu durante um ano, por meio de observações, informações de crianças. Castro não deixou claro como essas observações foram desenvolvidas, mas ressalta algumas de suas constatações. Em primeiro lugar, afirma que, na criança, o desenvolvimento do senso estético se faz muito lentamente, diferindo-se do senso estético do adulto. Outra constatação é a de que, para a autora, "este sentimento é educável" (REVISTA DO ENSINO, 1929, p.9). Por fim, chama a atenção para o fato de o mundo da arte, no período, ser "completamente fechado aos alunos da escola primária".

Para sanar esse problema, Castro considerou como urgente a tarefa de despertar, na criança, desde a sua entrada na escola, o gosto e o interesse pelo belo. A principal maneira de alcançar esse objetivo seria a partir da organização da escola, considerada, naquele momento, como "um dos maiores fatores de educação estética" (REVISTA DO ENSINO, 1929, p.9). Face à importância concedida ao assunto pela Revista, será apresentada, no tópico 5, uma discussão mais detalhada sobre esse ponto.

Anibal Matos (1933) também ressaltou a importância da educação para o aprimoramento do senso estético e destacou a centralidade das disciplinas de desenho e modelagem para se atingir tal objetivo. A educação dos sentidos, por sua vez, possibilitaria o desenvolvimento estético. Concebendo a questão de maneira mais estreita, contudo, para

\footnotetext{
${ }^{13}$ Professora da Escola Normal Modelo de Belo Horizonte.
} 
Matos, os sentidos teriam, "antes de tudo, um destino utilitário". Isso porque foram considerados por ele como responsáveis pela conservação da vida física: "vista, ouvido e tato nos guiam para evitar perigo e discernir o que nos é útil; gosto e olfato concorrem à nutrição".

Assim, o aprimoramento da percepção estética por meio da educação parece ter ocupado posição secundária para Anibal Matos: “Além dessa função (utilitária), em certos casos, (os sentidos) também são suscetíveis de um exercício desinteressado e então nos levam a sentir impressões de natureza estética" (REVISTA DO ENSINO, 1933, p.6).

O desenvolvimento do senso estético também esteve relacionado, em artigos publicados na Revista, à natureza, concebida como fonte inspiradora da arte. Segundo Castro: "a natureza, a única e verdadeira escola, será a maior das mestras". Nesse sentido, Castro recomendava que os alunos das escolas primária e secundária, em passeios, excursões e viagens, levassem consigo caderninhos. Neles deveriam ser realizadas anotações e croquis “do que de mais belo vissem"(REVISTA DO ENSINO, 1929, P.10). Nota-se também a vinculação do belo ao conceito de arte da época. As palavras de Castro reiteram tal afirmação e destacam o papel da professora no desenvolvimento da noção do belo:

A professora perfeitamente educada, guiará os seus discípulos, fazendo-os sentir, se souber sentir, as alegrias do belo, que são, segundo o grande o imortal filósofo italiano Paulo Mantegazza, as mais puras e democráticas (REVISTA DO ENSINO, 1929, P.11).

A ênfase dada à natureza como fonte inspiradora para o desenvolvimento estético revela a influência do romantismo ${ }^{14}$ nas concepções de arte presentes na revista.

\subsection{Influência do Romantismo no ensino do desenho}

O culto à natureza e à imaginação constituiu-se em uma das características centrais do romantismo. ${ }^{15}$ Assim, além do caráter utilitário a ele atribuído nos textos da Revista, o desenho também foi considerado como um importante veículo para o desenvolvimento de uma atitude de contemplação da natureza.

Na educação artística, no ensino do desenho, pode a criança dar voltas às suas faculdades criadoras, baseadas na realidade, isto é, voltadas para a contemplação da natureza, fonte maravilhosa de todas as formas de beleza (REVISTA DO ENSINO, 1933, p.11).

\footnotetext{
${ }^{14}$ Segundo a Enciclopédia de Artes Visuais Itaú Cultural: “(...) menos que um estilo ou escola, o romantismo faz referência a uma visão de mundo mais ampla que se dissemina por toda a Europa, entre meados do século XVIII até fins do século XIX, A visão romântica anuncia uma ruptura com a estética neoclássica, com a visão racionalista da época da Ilustração, Se o termo "clássico" remete à ordem, ao equilíbrio e à objetivação, a designação "romântico" apela às paixões, às desmedidas e ao subjetivismo". Disponível em: http://www.itaucultural.org.br/AplicExternas/enciclopedia_IC/index.cfm?fuseaction=termos_texto\&cd_verbete= 3640. Data de acesso: 16 nov. 2013.

15 Para uma discussão aprofundada sobre o assunto, ver: Favero. "O Romantismo e a Estetização da Natureza”. Disponível em: http://www.ceart.udesc.br/dapesquisa/files/9/02VISUAIS_Franciele_Favero.pdf. Data de acesso: 21 nov. 2013.
} 
Outro trecho da Revista também destaca a natureza como fonte de inspiração não apenas para o aprendizado do desenho, mas ainda para o desenvolvimento intelectual e moral: "A natureza devidamente observada e interpretada, será o modelo perfeito no qual encontrarão os estudantes um centro de interesse para o cultivo de suas faculdades intelectuais e morais" (REVISTA DO ENSINO, 1930, p.35).

\title{
3.2 Contribuições da psicologia
}

Além da contemplação da natureza, a criança deveria ser incentivada a cultivar a beleza do seu próprio corpo por meio do exercício físico. Considerando a beleza de maneira mais ampla, contudo, Castro salienta: "que a criança compreenda que a sua beleza se resume num conjunto de ritmos e de formas que se exprimem pela sua alegria". E, mais adiante, "o riso deve, portanto, ser o deus escolar" (REVISTA DO ENSINO, 1929, p.11). Nota-se, nessa última afirmação, uma clara rejeição ao modelo de ensino tradicional baseado, sobretudo, na ênfase da seriedade e passividade do aluno. A afirmação de Castro pode, portanto, ser considerada como uma das frases dos textos analisados que melhor expressa a essência do que se entendeu por Escola Nova.

A criação de um clima educacional favorável ao desenvolvimento da criança implicou na tentativa de introdução de algumas mudanças quanto à postura do professor. Especificamente sobre o ensino de desenho, foi recomendado, em textos da Revista, que a intervenção docente fosse "muito criteriosa":

\begin{abstract}
Em vez de uma cega imposição ou uma crítica desfavorável e intempestiva, de efeitos certamente contraproducentes, proveitosa será, ao contrário, uma orientação segura, de maneira que o aprendiz, em vez de ser um autômato, compreenda o valor de seu esforço pessoal. Indicar, sugerir, animar sempre, eis aqui o papel do mestre no ensino do desenho (REVISTA DO ENSINO, 1930, p.35).
\end{abstract}

A preocupação para com a criação de um clima favorável ao aprendizado no meio escolar marca a influência da psicologia na educação mineira. ${ }^{16}$ A presença da psicologia no campo educacional, naquele momento, despertou o interesse pelo desenvolvimento do grafismo infantil que, porém, é comparado por Anibal Matos, de modo bastante pejorativo, às representações gráficas de povos primitivos: "Seria longo enumerar as faltas que se notam nessas primeiras manifestações (povos primitivos). E que se repetem com uma interessante igualdade em todas as crianças” (REVISTA DO ENSINO, 1933, p.8). E, mais adiante: "Quem estuda as representações gráficas dos povos primitivos verá como se assemelham aos erros dos desenhos infantis" (REVISTA DO ENSINO, 1933, p.9). Tais erros eram atribuídos à "desproporção e absurdo" no traçado das formas, bem como à "falta de noção de impenetrabilidade".

\footnotetext{
${ }^{16}$ Durante as primeiras décadas do século XX, as teorias da psicologia passaram a ser consideradas como referência de fundamental importância para a educação escolar. No Brasil, a introdução do movimento escolanovista, a partir da década de 1920, marcou o desenvolvimento de um interesse pelas contribuições da psicologia para o contexto educacional.
} 
Ainda que as palavras de Anibal Matos expressem certo grau de preconceito no modo de avaliar as representações, tanto as de povos pré-históricos quanto as de crianças, torna-se evidente as contribuições da psicologia para o desenvolvimento de uma atuação mais respeitosa por parte dos adultos no que se refere aos desenhos infantis: "Nessa primeira fase (do desenvolvimento gráfico) a criança deve ficar em liberdade, porque os erros que ela pratica não podem ser corrigidos sem grave prejuízo" (REVISTA DO ENSINO, 1933, p.9).

\section{Escola como "fator" da Educação Estética}

A escola foi considerada, no período, como um dos fatores principais para a educação estética. Nessa perspectiva, deveria ser dado destaque ao prédio escolar, uma vez que: “A criança não sentirá dificuldade em entender, num edifício de belo estilo arquitetônico, mais que qualquer arte, as relações do útil com o belo" (REVISTA DO ENSINO, 1929, p.10).

Para Castro, o edifício escolar deveria "compreender uma estética simples, procurando de preferência os efeitos do estilo aos do adorno, para que desde a entrada da criança no edifício escolar, receba uma lição de arte"(REVISTA DO ENSINO, 1929, p.10). A recusa pelos excessos decorativistas na arquitetura é outra característica do neoclassicismo.

Por outro lado, tanto Castro (1929) quanto Anibal Matos (1933) consideraram que o ambiente escolar deveria ser alegre, decorado e florido. A ornamentação ficaria a cargo dos alunos, sendo realizada a partir de: flores colhidas, o que proporcionaria à escola um aspecto de mais intimidade; frisas e faixas decorativas confeccionadas em cartolina e utilizando-se modelos do natural - peixes, insetos, a própria criança etc. (REVISTA DO ENSINO, 1929, p.10).

Anibal Matos, por sua vez, acrescenta um elemento interessante na decoração do ambiente escolar. Segundo o autor, as salas de aula deveriam ser adornadas com "verdadeiras obras de arte ou boas reproduções das mesmas, principalmente de artistas nacionais" (REVISTA DO ENSINO, 1929, p.10). Tal proposição pode estar vinculada ao fato de Anibal ter sido, além de professor e inspetor de desenho, artista influente no contexto mineiro.

\section{Exposições escolares}

Em várias das edições consultadas da Revista, existiu uma sessão intitulada "Exposições Escolares" em que se destacava a importância da realização de exposições anuais.

O professor e diretor do Segundo Grupo Escolar de São Carlos, ${ }^{17}$ José Ferraz de Sampaio Penteado, explicita, de maneira entusiástica, o caráter atribuído à exposição anual para o contexto educativo: "A exposição final, nos estabelecimentos de ensino, deve ser uma narração muda, porém eloquente, do que se faz no correr do ano" (REVISTA DO ENSINO1930, p.94).

Em outro artigo da revista, também publicado no ano de 1930, Maria Alice Diniz ${ }^{18}$ indica, de maneira bastante clara, qual deveria ser o conteúdo das exposições: “A exposição anual é um conjunto de todos os bons trabalhos executados durante o ano. Trabalhos manuais, desenho, provas escritas, etc. serão elementos da exposição" (REVISTA DO ENSINO, 1930, p.141).

\footnotetext{
${ }^{17}$ Não foram encontradas informações a respeito do Segundo Grupo Escolar de São Carlos.

18 Professora técnica do grupo escolar "Modestino Gonçalves", localizado no município de Santa Luzia, Minas Gerais.
} 
Embora seja afirmado na Revista que "quase todas as disciplinas poderão oferecer elementos para exposição" (REVISTA DO ENSINO, 1930, p.94), verifica-se grande ênfase nas possibilidades proporcionadas pelas disciplinas de desenho e de trabalhos manuais nesse contexto. Especificamente sobre o desenho nas exposições, Penteado afirmou:

É uma disciplina que oferece bastante margem: além do programa de desenho propriamente dito, ainda temos o desenho aplicado, como a representação de fatos históricos, fatos da vida social, higiene, educação no lar e na escola, histórias mudas e outras (REVISTA DO ENSINO, 1930, p.94).

As palavras de Penteado descrevem com bastante precisão um aspecto importante quanto ao ensino de desenho segundo a pedagogia escolanovista: a sua integração com as demais disciplinas, uma vez que o desenho foi considerado como uma ferramenta preciosa para a internalização, ilustração e fixação de conceitos.

A organização das exposições deveria envolver a participação ativa dos alunos, desde a escolha dos trabalhos e do local onde aconteceriam até a atuação como guias dos visitantes. Objetivava-se com isso que as crianças desenvolvessem habilidades como: iniciativa, julgamento, saber receber críticas e o gosto estético. Outro objetivo do evento foi promover uma maior aproximação da escola com a família, já que seus membros eram convidados a visitá-lo. Nessas ocasiões, as crianças seriam ainda estimuladas a praticarem "boas maneiras sociais" (REVISTA DO ENSINO, 1930, p.141).

As exposições anuais também deveriam acontecer nos cursos de formação de professores. Dois artigos da Revista, ambos publicados no ano de 1930, destacam o trabalho desenvolvido pela professora Artus Perrelet, ${ }^{19}$ junto às suas alunas da Escola de Aperfeiçoamento. ${ }^{20}$

Para a exposição anual do curso de desenho ministrado por Perrelet, foram selecionados, dentre os seis mil trabalhos submetidos a "rigorosa triagem", centenas deles. $\mathrm{O}$ grau de prestígio alcançado pela professora no contexto educacional mineiro pode ser constatado na Revista. Segundo um artigo de autor desconhecido, publicado no ano de 1930, na seção de desenho e modelagem da exposição anual realizada na Escola de Aperfeiçoamento, "se acusam os dotes excepcionais do rico e colorido espírito de madame Artus Perrelet”. E mais adiante:

19 Artus Perrelet, pesquisadora do desenho infantil no Instituto Jean Jacques Rousseau, dedicou-se a divulgar os métodos de ensino por ela desenvolvidos neste campo em vários países da Europa e da América (BARBOSA, 2002, p.63).

${ }^{20}$ Criada em Belo Horizonte, no final da década de 1920, a instituição teve como objetivo principal o aperfeiçoamento de professores do ensino primário, diretores dos grupos escolares e assistentes técnicos. Além de se constituir como um centro de formação de recursos humanos, revelou-se como "um laboratório de pesquisas e experimentação, num importante centro de testagem de novos métodos de ensino" (PEIXOTO, 2003, p.41). 
Essa grande educadora suissa, aplicando as diretrizes do seu famoso método ${ }^{21}$ de desenho, conseguiu renovar por completo esse ensino entre nós. É uma esteta de boa linhagem, com o dom de imprimir um como sentido místico e espiritual às coisas sobre que se exerce sua sensibilidade (REVISTA DO ENSINO, 1930, p.64).

\section{A disciplina de Trabalhos Manuais na Escola Nova}

De acordo com a discussão apresentada no tópico 3, o destaque concedido aos trabalhos manuais, naquele momento, esteve ligado à necessidade de superação do desenvolvimento de uma educação passiva, marcada pelo verbalismo excessivo. Segundo Lourenço Filho (1929, p.6), citado por Horta (1933, p.4):

Mas, se há trabalho intelectual e trabalho manual, não há dúvida em que o trabalho intelectual isolado leva às aberrações do verbalismo, da formação intelectualizada pura, sem finalidade para as atividades normais, por um lado, e sem assento, por outro, na afetividade criadora e mobilizadora natural da criança. Donde ser o centro da irradiação moderna da didática o próprio trabalho com as mãos (REVISTA DO ENSINO, 1933, p.4).

Em um artigo intitulado $O$ ensino de trabalhos manuais, datado de 1933, R. Tavares, assistente técnico regional, também argumenta sobre a necessidade de integração entre corpo e mente na educação:

A escola nova encara a atividade mental e a corporal, como duas expressões do mesmo dinamismo psíquico da personalidade humana. Daí a necessidade do consórcio dessas mesmas forças como um imperativo categórico da educação (REVISTA DO ENSINO, 1933, p.58).

Tal aspecto reitera a influência da psicologia no ensino de arte naquele momento, conforme apontado no tópico 3.2, relativo ao ensino de desenho. De acordo com R. Tavares: "Na concomitância, pois, das duas atividades (mental e corporal) assenta um dos princípios fundamentais da escola moderna, de acordo aliás, com as leis da psicologia infantil" (REVISTA DO ENSINO, 1933, p.58).

\subsection{Utilitarismo e Trabalhos Manuais}

A máxima do "aprender fazendo", amplamente veiculada durante o período enfocado, não esteve relacionada, contudo, apenas a uma visão de educação mais ativa, em que a ação infantil contribuiria para a aquisição de conhecimentos. A defesa de uma educação que se baseasse na atividade da criança esteve muitas vezes ligada a interesses econômicos mais amplos.

\footnotetext{
${ }^{21}$ Considerando-se que o presente artigo tem seu foco de discussão no ensino de desenho no curso primário, não será apresentada aqui uma discussão pormenorizada sobre o assunto. Para uma análise aprofundada do método de ensino de desenho desenvolvido por Perrelet e aplicado no curso de formação de professores em Minas Gerais, ver: Barbosa (2002).
} 
Para Horta, por exemplo, a atividade manual "precisa em nossas escolas de ocupar um lugar bem mais importante, de modo a garantir uma disciplina de trabalho necessária ao equilíbrio econômico, ao êxito individual e coletivo" (REVISTA DO ENSINO, 1933, p.5).

A vinculação da educação com o preparo profissional fica bastante evidente em outra afirmação da autora: "Educar é agir externa e internamente, concomitantemente. E agir implica o máximo de trabalho braçal, sobretudo, em um país como o nosso, onde o problema econômico depende de braços" (REVISTA DO ENSINO, 1933, p.8).

Nesse sentido, "a formação profissional iniciada nos trabalhos manuais e concluída em cursos técnicos" deveria constituir-se, de acordo com o educador mineiro Firmino Costa (REVISTA DO ENSINO, 1931, p.69), em uma das grandes diretrizes da educação.

Nas palavras do educador, fica evidente a relação que se estabeleceu entre o ensino de trabalhos manuais e a formação profissional iniciada ainda no curso primário. Esse direcionamento dado à educação foi percebido, no período, como necessário para o progresso econômico do país:

Educar pelo trabalho é preparar a inteligência-ação, síntese da aspiração nacional, segredo do invejado progresso de outros povos, tão ambicionado, mas que não realizamos, porque talvez nos percamos em estéreis idealizações escolares ou doentios programas feitos, com finalidade em si mesmos (REVISTA DO ENSINO, 1933, p.8).

\subsection{O espaço ocupado pelos trabalhos manuais na prática das escolas}

Embora o trabalho manual tenha sido considerado, no plano do discurso, como um dos elementos mais importantes da Escola Nova, o descaso com relação a essa atividade, na prática das escolas, parece não ter sido superado:

Não se pode compreender como, em pleno prestígio da escola ativa, o trabalho manual seja tão apagado na vida dos grupos, tão desprestigiado, esperando que sobre tempo à alfabetização para que seja dado (REVISTA DO ENSINO, 1933, p.3).

A afirmação acima se constitui em denúncia de um problema ainda não superado nos dias de hoje: a existência de uma hierarquia entre as disciplinas que compõem o currículo escolar.

O ano de 1933 parece ter sido marcado pela denúncia da distância entre o discurso educacional oficial de valorização dos trabalhos manuais e o que de fato acontecia nas escolas. Assim, R. Tavares, em um dos artigos da Revista, também afirmou que os trabalhos manuais não estavam sendo realizados em todos os estabelecimentos de ensino. $\mathrm{O}$ autor ainda acrescenta: "Deixo aqui nestas linhas, os meus melhores votos, para que isso se dê, no mais curto prazo, de acordo, aliás, com o pensamento da Inspetoria Geral da Instrução" (REVISTA DO ENSINO, 1933, p.59).

O problema envolvendo o descaso quanto aos trabalhos manuais, porém, pareceu estar relacionado a questões mais amplas, indo além dos entraves existentes no interior das escolas: 
Não é apenas dos grupos o seu papel de desprestígio. Os mais apaixonados entusiastas do nosso magno problema gabam-se, com uma certa displicência, de que não entendem de trabalhos manuais. Daí, em parte, o seu lugar precário na vida escolar (REVISTA DO ENSINO, 1933, p.3).

Embora não fique claro, na afirmação de Horta, quais sejam "os mais apaixonados entusiastas do problema", deduz-se que essas pessoas sejam autoridades do ensino. De acordo com Ana Mae Barbosa (1986), o preconceito quanto às artes no Brasil tem origens históricas que remontam à educação jesuítica, primeiro modelo educacional implantado no país. Sendo pautado, predominantemente, na palavra escrita e falada, pouco ou nenhum espaço restaria para o desenvolvimento de uma educação mais prática.

Identifica-se ainda outro importante fator explicativo para a situação de desprestígio das artes no contexto educacional brasileiro. Segundo Romanelli (1978), o fato de o país ter tido a escravidão como forma de relação social de produção, desde o período colonial até pouco antes do final do segundo reinado, contribuiu para o desenvolvimento de um forte preconceito contra as atividades de ordem prática. Considerando-se que as artes estiveram tradicionalmente ligadas ao campo do manualismo, não é de se estranhar os entraves que marcaram e marcam a sua inclusão na educação escolar.

\section{Considerações Finais}

Tanto a quantidade de artigos quanto o modo como o Desenho é tratado nos textos publicados na Revista revelam que esta disciplina recebeu maior valorização no contexto da Escola Nova em Minas do que a disciplina de Trabalhos Manuais. Isso significa que o peso da tradição, expressa na influência do neoclassicismo e do liberalismo, foi mais forte no ensino de arte, naquele momento, do que o lema do "aprender fazendo", tão caro ao discurso escolanovista. Para Corinto da Fonseca (s.d., p.26), destacado educador do período:

Trabalhos Manuais servem para que todas as coisas novas dos programas sejam aprendidas. Exercícios que são da faculdade da realização do indivíduo a educar, tornando mais real, mais efetivo, mais radicado o conhecimento de todas elas, servindo-lhes de fixativo.

Porém, entraves existentes no interior da escola e fora dela, conforme exposto no tópico anterior, não permitiram que a disciplina de Trabalhos Manuais desfrutasse do mesmo prestígio que a disciplina de Desenho.

Um aspecto comum se faz notar, contudo, entre as duas disciplinas: muito para além de preocupações de cunho pedagógico, a orientação dada ao ensino de arte, naquele momento, teve como intuito contribuir para a preparação profissional, preparação esta que deveria ser desenvolvida desde os primeiros anos de escolaridade. Aqui, o destaque conferido à disciplina de Trabalhos Manuais torna-se mais evidente, corroborando o estudo de Hoeller e Daros acerca de sua função no ensino primário e profissional, nos anos de 1920, para a construção da "nação laboriosa". As autoras ampliam a discussão do tema ao analisarem a influência de questões sociais na orientação dada ao ensino de Trabalhos Manuais nos níveis de ensino assinalados. Embora a ligação entre essa última disciplina e o desenvolvimento de uma 
educação utilitarista seja mais evidente, sugere-se o desenvolvimento de outros estudos que busquem apreender com maior profundidade o papel do desenho na educação primária e o contexto social mais amplo, no período tratado, considerando-se a tradicional centralidade por ele ocupada na educação escolar.

\section{Referências}

AZEVEDO, Fernando. A Cultura Brasileira. Rio de Janeiro: Instituto Brasileiro de Geografia e Estatística, 1943.

BARBOSA, Ana Mae Tavares Bastos. John Dewey e o Ensino da Arte no Brasil. 5. ed. São Paulo: Cortez, 2002.

. Tópicos utópicos. Belo Horizonte: Ed. Com/Arte, 1998.

. História da Arte-Educação. São Paulo: Max Limonad, 1986.

FERRAZ, Maria Heloisa C. de T.; FUSARI, Maria Felisminda de R. Arte na Educação Escolar. São Paulo: Cortez, 1992.

FONSECA, Corinto da. A Escola Ativa e os Trabalhos Manuais. São Paulo: Edições Melhoramentos, sd.

HOELLER, Solange Aparecida de Oliveira; DAROS, Maria das Dores. Trabalhos manuais no ensino primário e no ensino profissional para a construção da nação laboriosa: proposições de Orestes Guimarães e Corinto da Fonseca - Brasil, anos de 1920. X ANPED SUL, Florianópolis, out., 2014.

LIBÂNEO, José Carlos. Democratização da Escola Pública. São Paulo: Loyola, 1990.

MINAS GERAIS. Decreto no 7970-A, de 15 de outubro de 1927; Regulamento do Ensino Primário. Coleção das Leis e Decretos do Estado de Minas Gerais, Belo Horizonte: Imprensa Oficial, v.1, p.1139-1298, 1928.

PEIXOTO, Ana Maria Casasanta. Educação e Estado Novo em Minas Gerais. São Paulo: EDUSF, 2003.

PEREIRA, Denise Perdigão. Que arte entra na escola através do currículo? Entre o utilitarismo e a possibilidade de emancipação humana pela arte, nos programas de 1928 e 1941, na Escola Nova em Minas Gerais. 2007. 157f. Dissertação (Mestrado em Educação) Pontifícia Universidade Católica de Minas Gerais, Belo Horizonte, 2007.

REVISTA DO ENSINO. Belo Horizonte: Imprensa oficial, 1926-1933. Mensal.

ROMANELLI, Otaíza de Oliveira. História da Educação no Brasil (1930/1973). Petrópolis: Vozes, 1978.

RODRIGUES, R. L. Eu Sonhava em Viajar sem Saber aonde ia... Entre Bruxelas e Belo Horizonte: itinerários da escultora Jeanne Louise Milde de 1990 a 1997. 2001. Dissertação (Mestrado em História) - Universidade Federal de Minas Gerais, Faculdade de Filosofia e Ciências Humanas, Belo Horizonte. 